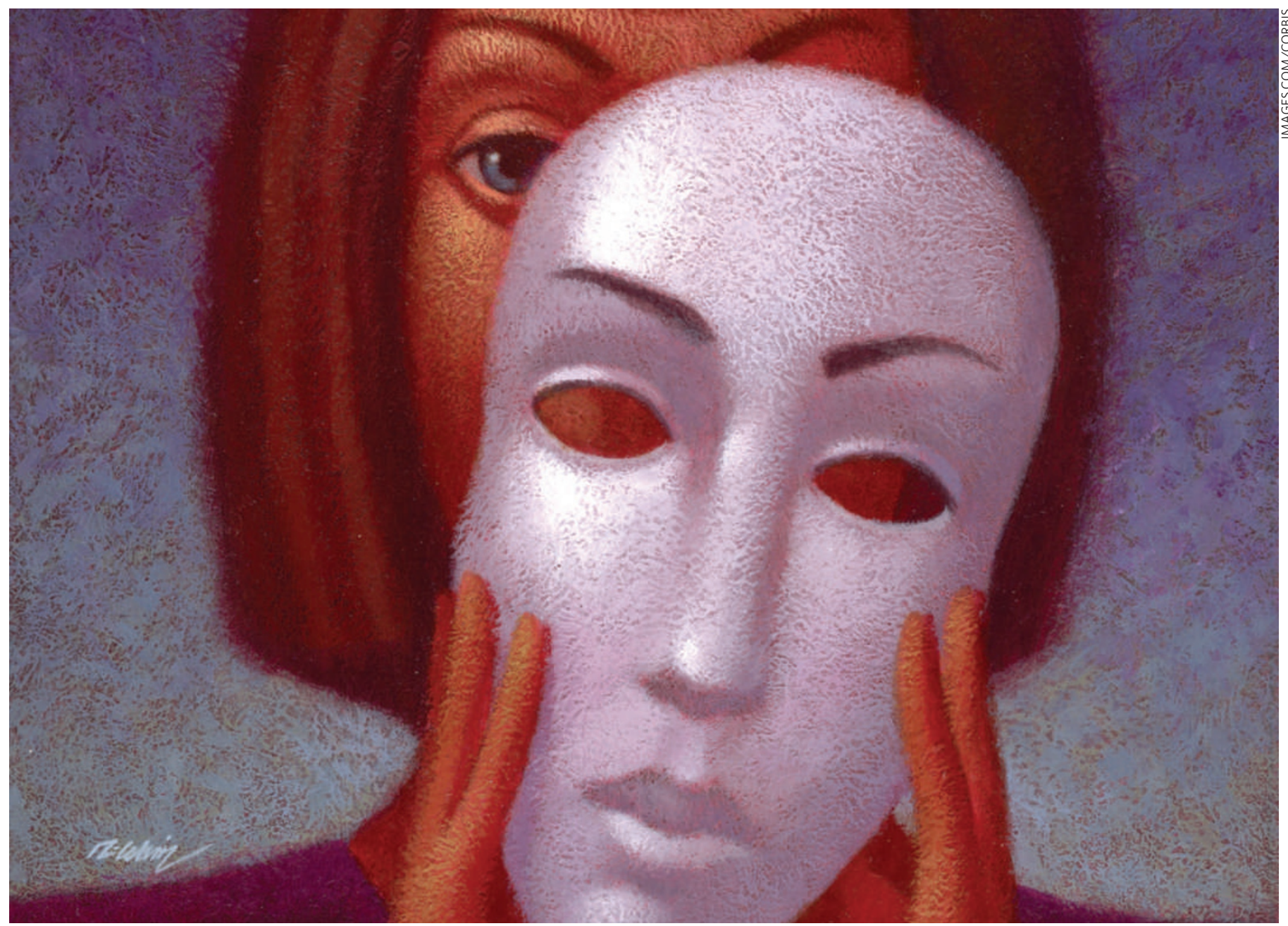

\title{
Unmasking the impostor
}

\section{Feelings of inadequacy in one's field sometimes plague even the most accomplished scientists, especially women. Karen Kaplan analyses this apparent phenomenon and its impact.}

t usually happens to Cherry Murray when she is about to write a paper or give a talk on a new finding or discovery. The thoughts come unbidden,

hammering inside the physicist's head: 'I can't do this. I haven't done enough experiments. I haven't got enough data. I can't write the paper well enough yet or give the talk.'

These aren't the routine self-doubts of a young researcher. Murray is principal associate director for science and technology at Lawrence Livermore National Laboratory (LLNL) in California, and president of the American Physical Society. On 1 July she will become dean of Harvard University's School of Engineering and Applied Sciences. Referring to her work, she says: "I have to tell myself this doesn't have to be perfect."

What Murray describes - an overwhelming sense of being a fraud, a phony, of not being good enough for her job, despite much evidence to the contrary - was first identified more than 30 years ago by two clinical psychologists who dubbed it the 'impostor phenomenon' (IP) (P. Clance and S. Imes Psychother. Theor. Res. 15, 241-247; 1978). In their paper, Pauline Clance and Suzanne Imes describe women who, despite reaching significant intellectual milestones ranging from advanced degrees to professional awards, cannot internalize their success or convince themselves they deserve it. "They consider themselves to be 'impostors," wrote Clance and Imes. "Numerous achievements, which one might expect to provide ample objective evidence of superior intellectual functioning, do not appear to affect the impostor belief."

Before taking up her LLNL post, Murray spent decades at Bell Laboratories and left as senior vice-president for physical sciences and wireless research. She has published more than 70 papers in peer-reviewed journals, has won a number of awards, holds two patents and has served on more than 80 national and international scientific committees and governing boards. Yet the self-doubt still lurks. "Do I ever think I'm not qualified?" she says. "All the time.”

\section{Not a syndrome}

Although often referred to as the impostor syndrome', the affliction is not recognized medically as a syndrome - a group of symptoms signifying a disease or the propensity to develop one. In their 1978 paper, Clance and Imes deliberately avoided using the word syndrome. "I didn't want this to be one more way of pathologizing women," says Clance. She and Imes initially believed the affliction affected mainly women, but later research has shown that men fall prey as well. Many people identify themselves as sufferers, but it's a matter of debate as to whether IP is actually a distinct emotional or psychological condition. "A whole lot more has been made of this for commercial purposes than it deserves," says Mayada Akil, medical director of the 
outpatient programme in the psychiatry department at Georgetown University Hospital in Washington DC. In recent years, it has drawn significant interest as the subject of books, talk shows and popular-magazine articles. "I think the emotional experience exists, but it is not a disorder or syndrome," says Akil. Rather, she suggests, other underlying maladies such as depression are responsible for severely impeding work. Depression is a true disorder, she says.

But for believers such as Clance and Imes, IP is a real condition that often has serious consequences. It may emotionally choke its sufferers to the point at which it derails their career. offered this promotion, but she decided she didn't have the skill set to accept it. She declined," Clance remembers. Although this story has a happy ending - the client's unusually perceptive superior encouraged her to accept the new post and told her she could return to her former post if things didn't work out - many don't, Clance warns.

\section{The search for perfection}

Catherine Cardelús, an assistant professor in biology at Colgate University in Hamilton, New York, first noticed the phenomenon as a graduate student working in the rainforests of Costa Rica. Cardelús is physically fit, and her studies involved a great deal of challenging field work, such as climbing trees, and much intensive lab work. "I was thinking, 'I'm not cut out for this. I really can't do this' - even though there was ample evidence to the contrary," she remembers. And the negative, selfsabotaging thoughts didn't stop, they continued through her postdoc and into her full-time positions. "I'm a high achiever and I'm successful, but I've had those moments of waiting for someone to tap me on the shoulder and tell me I don't belong," she says. "Or to tell me I was really lucky to get that paper in that journal." Cardelús has discussed the issue at international science conferences. "It's pervasive," she says. "Absolutely pervasive."

Clance, a professor emeritus at Georgia State University in Atlanta and a clinical psychologist since 1976, calls Murray's and Cardelús's experiences "classic IP". Neither she nor Imes, a psychotherapist and clinical psychologist in Atlanta, can definitively say whether women in science suffer from the breeze. "A lot of high achievers grew up in families where they are given approval for achievement but not given much validation for their feelings," Imes explains. “So they grow up thinking their worth or value is tied only to achievement."

New York University neuroscientist David Poeppel struggled for years with impostor feelings that emerged when he was a graduate student at the Massachusetts Institute of "One of my clients had been

Technology and continued to plague him through his postdoc at the University of California, San Francisco. "I was working on research I thought was innovative, but was surrounded by overachievers," he says. "You think, 'I couldn't have done that. How come I'm even here at all?'” It still sometimes raises its unwelcome head. "Exogenous validation doesn't do it," Poeppel says. "Somehow, you can't internalize. You cannot say, 'All right, what I'm doing is serious and is taken seriously problem in greater numbers than those in other fields or than men in any field.

Although Murray and Cardelús say it has not damaged their careers, both admit they haven't published as many papers as some of their male counterparts - perhaps in part because neither can bear to have so much as a typo mar their work. So they review, rewrite, proofread, review, rewrite and proofread. The process can take years. "I sit on my papers," says Cardelús. "I make sure there's not a single typo and if there is, it's a disaster." Indeed, the need for perfectionism is a hallmark of feeling like an impostor, according to Clance and Imes. "They have to be the perfect hostess and mother and wife. They have to be perfect at everything," says Imes.

What causes this emotional selfsabotage? Clance and Imes found that childhood experiences typically begin the cycle. Sufferers were often valued for their intelligence, giving rise to self-doubts and feelings of fraudulence when excellent grades don't materialize in graduate school and, later, when a new postdoc or new job isn't a

\section{PURGING THAT INNER CRITIC}

Here are some strategies that may help those struggling with impostor phenomenon.

- If you're a student or a postdoctoral fellow, get a supportive, understanding adviser.

- If you're working, do your best to find a supportive, understanding mentor.

- Call on your partner or friends to be supportive and talk you through impostor feelings.

- Hire a tutor or take a class in a topic or area where you think your abilities are weaker. You'll learn what you need - or realize how much you already know.

- Make a list of your strengths. Look back at examples of your own successful work, or positive reviews, and remind yourself of your own accomplishments.

- Accept that some tasks will not be done perfectly.

- Be aware of your language choices. If you find yourself thinking you were 'lucky' to have got a grant or published a paper, focus on what you did to earn it. 